Journal homepage:

http://www.jurnalmetal.or.id/index.php/jmi

P-ISSN: $0126-3463$

e-issn : 2548-673X

\title{
PEMODELAN 3D INTAKE MANIFOLD BERBASIS FITUR
}

\author{
Haruman Wiranegara dan Pujiyanto \\ Balai Besar Logam dan Mesin (BBLM), Kementerian Perindustrian \\ Jl. Sangkuriang No. 12 Kota Bandung, Jawa Barat 40135 \\ Email: haruman@kemenperin.go.id,pujiyanto@kemenperin.go.id
}

Diterima: 09 Desember 2016; Diterima untuk revisi: 20 Februari 2017; Diterima: 20 Maret 2017;

Publikasi online: 29 Maret 2017

\begin{abstract}
ABSTRAK
Salah satu upaya untuk untuk menemukan kembali teknologi pembuatan suatu komponen otomotif dari impor adalah dengan melakukan rekayasa peniruan (reverse engineering). Pada penelitian ini telah dilakukan salah satu tahap penting dalam rekayasa peniruan yaitu pemodelan 3D intake manifold. Tujuan penelitian ini adalah menemukan geometrik dan dimensi yang tepat melalui proses pengukuran dan penggunaan fitur yang tepat dalam pemodelan 3D intake manifold. Langkah-langkah yang dilakukan adalah mempelajari fungsi komponen, mempelajari proses manufaktur, mempelajari fitur-fitur yang digunakan pada komponen intake manifold, melakukan pengukuran dengan pemindai 3D (3D scanner) dan alat ukur manual, melakukan pemodelan 3D, melakukan pengecekan menyeluruh semua fitur. Hasil menunjukan bahwa semua geometrik dan dimensi intake manifold dapat diidentifikasi dan terbentuk model 3D intake manifold.
\end{abstract}

Kata Kunci: Pemodelan 3D intake manifold, pemindaian 3D, berbasis fitur

\begin{abstract}
One of the efforts to reinvent the technology for the manufacture of an automotive component of the import is to do reverse engineering. This study has been carried out one of the important stages in the reverse engineering is a 3D modeling intake manifold. The purpose of this study is to find geometric and precise dimensions through the measurement process and the proper use of features in $3 D$ modeling intake manifold. The steps taken is studying the function of components, studying the manufacturing process, learn about the features that are used in the intake manifold components, perform measurements with a 3D scanner and manual measuring instrument, perform 3D modeling, perform a thorough check of all the features. Results showed that all geometric and dimensional intake manifold can be identified and created $3 D$ models intake manifold.
\end{abstract}

Keywords: 3D Modeling intake manifold, 3D scanning, based feature

\section{LATAR BELAKANG}

Indonesia merupakan negara dengan pengguna kendaraan roda empat terbesar di Asia, dengan besarnya konsumen kendaraan sehingga tumbuh industri PMA otomotif di Indonesia yang saat ini terbesar adalah Jepang, Jepang sebagai pemilik PMA terbesar industri otomotif di Indonesia memiliki hak design dan teknologi sehingga meraup banyak keuntungan dari konsumen lokal.
Untuk meningkatkan penyerapan tenaga kerja dan mendorong tumbuhnya industri dalam negeri maka pemerintah membuat kebijakan TKDN (tingkat komponen dalam negeri). Dengan adanya kebijakan TKDN maka industri lokal harus tumbuh sehingga bisa memasok sebagian komponen otomotif secara lokal after market. Hal ini diharapkan akan berdampak pada peningkatan penyerapan tenaga kerja. 
Untuk dapat membangun industri lokal maka perlu penguasaan teknologi otomotif, Penguasan teknologi masih harus bertahap dari komponen yang paling mudah sampai yang paling sulit, salah satu komponen yang bisa dikerjakan secara lokal adalah intake manifold. Intake manifold merupakan salah satu komponen penting dari enjin.

Untuk dapat diproduksi oleh industri kecil lokal di Indonesia perlu dilakukannya rekayasa peniruan agar dapat diproduksi secara lokal. Baik dari segi SDM maupun bahan baku. Lingling Lia, et.all (2017) menyatakan bahwa dengan bantuan reverse engineering (RE), dalam mengukur dan memperbaiki geometri akan cepat dan akurat, untuk remanufaktur menjadi komponen baru.

Salah satu komponen mesin otomotif yang akan dijadikan sasaran penelitian ini adalah Intake manifold enjin F10 Suzuki. Adapun alasan pemilihan komponen ini adalah kompleksitas dari komponen ini cukup tinggi sehingga bisa dijadikan acuan untuk pembuatan komponen intake manifold yang sejenis. Hal lain bertujuan menarik minat individu-individu peneliti untuk melakukan litbang enjin.

Produk komponen otomotif yang akan dibuat ini telah mempertimbangkan kemampuan personil dan peralatan pendukung untuk dilaksanakan, juga mempertimbangkan sistem secara keseluruhan, data, literatur, narasumber, peralatan, standar dan lain-lain tersedia

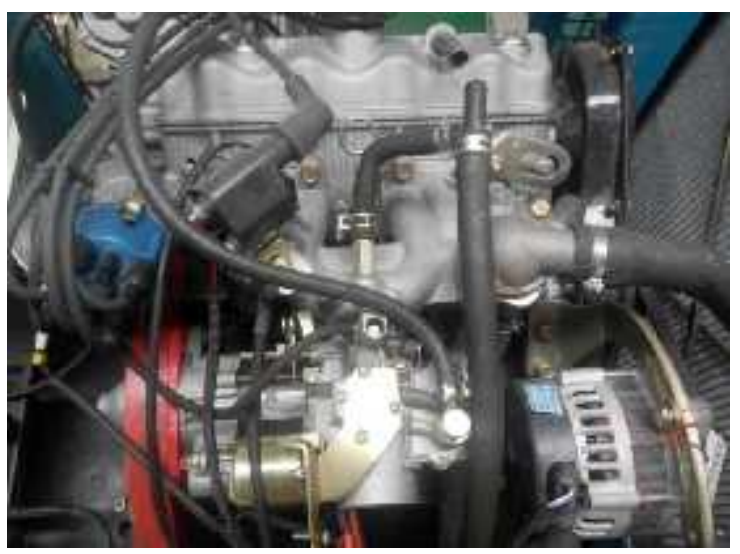

Gambar 1. Engine F10 Suzuki

\section{PERUMUSAN MASALAH}

Ada tujuh tahapan dalam rekayasa peniruan, yaitu:

1. Pengumpulan informasi mengenai produk yang ditiru

2. Analisis fungsi menyeluruh dan analis perbagian/ kelompok/subrakitan

3. Pengukuran dan pemodelan geometrik
4. Analisis keberfungsian, kehandalan dan keterbuatan.

5. Perwujudan produk hasil peniruan

6. Pengetesan dan penilaian ketercapaian peniruan.

7. Perbaikan dan persiapan produksi produk tiruan.

Salah satu yang harus dipecahkan pada kasus ini adalah Pengukuran dan pemodelan geometric, bagaimana mengukur untuk mendapatkan semua fitur-fitur yang digunakan dalam intake manifold sehingga geometrik dan dimensi intake manifold dapat digambarkan. Memprediksi dan menggambarkan fitur-fitur yang tidak mampu terukur oleh alat ukur namun tidak mengganggu fungsi dari komponen, tidak terjadi in coincident dan interference pada model yang akan menghambat messing pada saat simulasi dengan CAE. Michal Dúbravík et. All (2012) menyatakan bahwa Aplikasi reverse engineering dalam industri otomotif adalah bagian integral dari proses penciptaan mobil. scanner 3D yang paling digunakan oleh desainer mobil. Ini akan memakan waktu dan sulit untuk mentransfer model mobil, teknologi scanner 3D dan desainer dapat mentransfer desain dalam beberapa menit untuk software CAD.

\section{TUJUAN PENELITIAN}

Tujuan dari penelitian ini adalah mendapatkan/menemukan semua data intake manifold berupa fitur-fitur base pemodelan dari intake manifold yang terukur maupun yang tidak terukur.

ALAT BANTU DAN BAHAN PENELITIAN Bahan yang diperlukan untuk penelitian ini adalah Komponen Intake manifold Suzuki F10 hasil impor dan Die Penetrant yang berfungsi untuk membatu dalam proses pengukuran pemindai 3D agar hasil pengukuran lebih baik. Alat bantu yang diperlukan berupa Satu Set pemindai 3D, gauge califer dan Aplikasi Rapidform

\section{TAHAP-TAHAP PENELITIAN}

Adapun tahap-tahap penelitian yang dilakukan adalah:

1. Melakukan perencanaan pengukuran dan inspeksi

2. Mempersiapkan semua alat ukur

3. Melakukan Kalibrasi Alat ukur Pemindai $3 \mathrm{D}$ 
4. Melakukan perbandingan hasil alat ukur 3D pemindai dengan alat ukur manual.

5. Pengambilan data (Melakukan pengukuran menggunakan Pemindai 3D)

6. Analisis data hasil pengukuran (Melakukan pengecekan bagian-bagian yang tidak dapat diukur dengan pemindai 3D)

7. Melakukan Merge Point cloud (hasil pengukuran pemindai)

8. Melakukan Fitting point cloud

9. Melakukan Pengecekan Semua Ukuran Fitur

10. Melakukan pemodelan 3D

\section{HASIL DAN PEMBAHASAN}

a. Analisa fungsi

Intake manifold adalah bagian dari mesin yang memasok campuran bahan bakar/udara ke silinder (ruang bakar). Pada mesin berbahan bakar bensin dengan sistim karburator, fungsi utama dari intake manifold adalah untuk menyeragamkan distribusikan campuran pembakaran. Pada mesin fuel injection, intake manifold selain digunakan untuk mendistribusikan udara, juga digunakan untuk menempatkan nozzle dan sensor volume udara. Sedangkan pada mesin diesel intake manifold digunakan hanya untuk mendistribusikan udara saja.
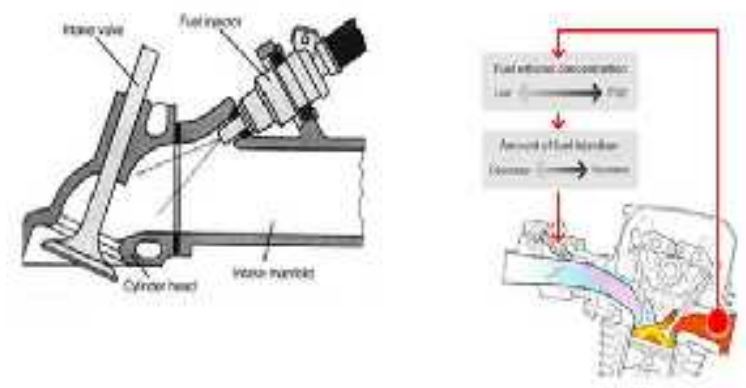

Gambar 2. Tempat penempatan fuel injector pada intake manifold

Pemerataan distribusi bahan bakar adalah penting untuk mengoptimalkan efisiensi dan kinerja mesin. Gerakan ke bawah dari piston dan pembatasan yang disebabkan oleh katup throttle, dalam spark ignition engine piston akan menyebabkan vacum parsial (lebih rendah dari tekanan atmosfer) di intake manifold. Manifold vacum ini sangat besar, dan dapat digunakan sebagai sumber tenaga mobil tambahan untuk mendorong sistem tambahan: rem power assisted, perangkat kontrol emisi, cruise control, pengapian muka, wiper, power window, katup sistem ventilasi, dll. Vacum ini juga dapat digunakan untuk menarik piston setiap blow-by gas dari crankcase mesin. Ini dikenal sebagai sistem ventilasi bak mesin positif. Dengan cara ini gas yang dibakar dengan bahan bakar / campuran udara.

b. Pembongkaran dan Analisa Fitur

Tahap awal adalah melakukan pembongkaran dan mengamati semua bagian intake manifold dan fitur-fitur yang digunakan dalam produk.

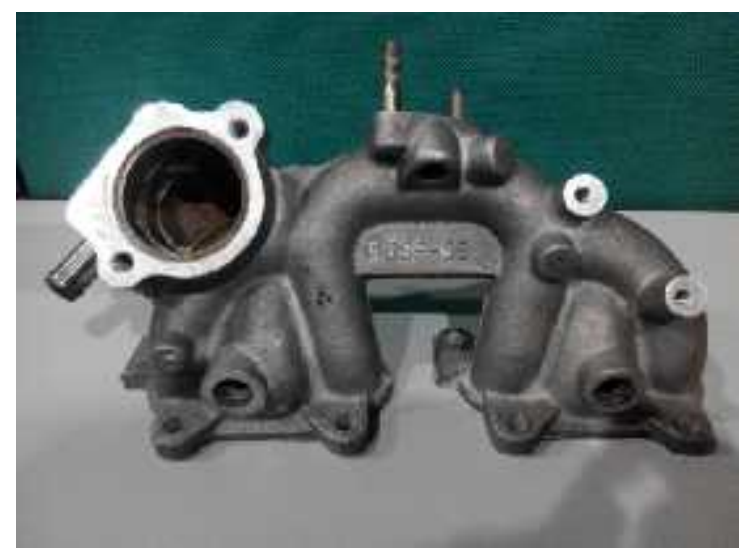

Gambar 3. Intake Manifold F10 Suzuki

Analisis fitur pertama kali di bandingkan dengan primitif model antara lain cube, rectangular prism, triangular prism, sphere, cone, torus dan cylinder

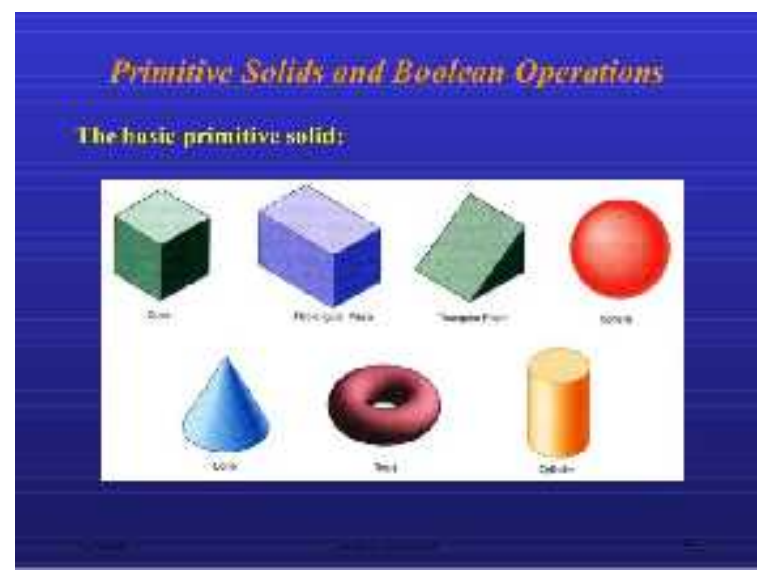

Gambar 4. Primitif Fitur

Hasil pengamatan menunjukan bahwa sebagian fitur yang digunakan pada intake manifold adalah menggunakan primitive pemodelan berupa: Sphere, Plane, Torus, dan cylinder. Adapun fitur editing yang digunakan: sweep dan fillet. Dengan fiturfitur primitive dan fitur editing maka 
intake dapat digambarkan. Pendekatan fitur primitive dilakukan sehubungan pendekatan yang dimabil adalah berbasis fitur.

c. Pengukuran dengan 3D pemindai

Tahap selajutnya adalah mengukur semua bagian intake manifold engine F10 suzuki dengan menggunakan dua alat ukur, yaitu: Scan 3D noncontact Merk Vivid dan Califer dengan merk Mitutoyo. Hasil dari Scan 3D memperoleh data ukuran berupa point cloud.

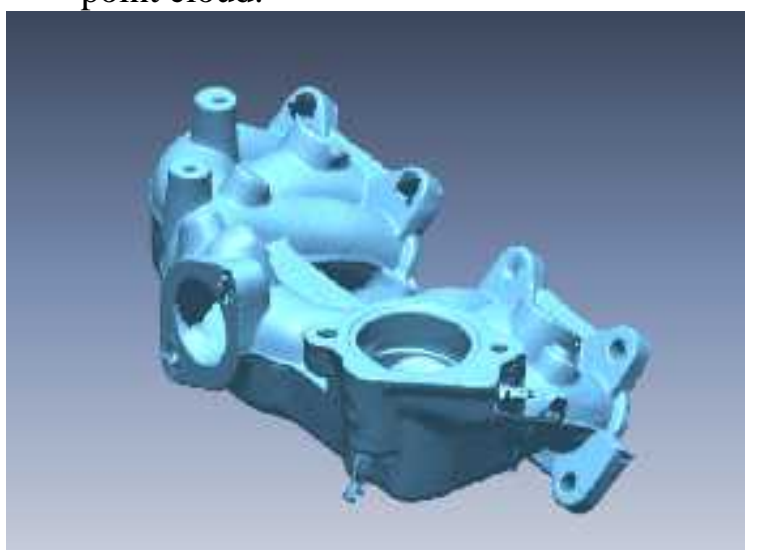

Gambar 5. Point Cloud (hasil pengukuran dengan 3D pemindai non contact)

Pada hasil pengukuran diatas menunjukan bahwa tidak semua bagian dapat diukur ini disebabkan karena keterbatasan kemampuan alat ukur, pada gambar hasil terlihat bagian lubang baut tidak terukur dengan lengkap, bagian dalam dari intake sebagian besar tidak didapat diukur karena tidak terkena sinar scan, juga beberapa bagian lain ada yang tidak lengkap terukur. Dari hasil pengukuran terlihat pada gambar menunjukan ada beberpa bagian yang tidak terukur yaitu:

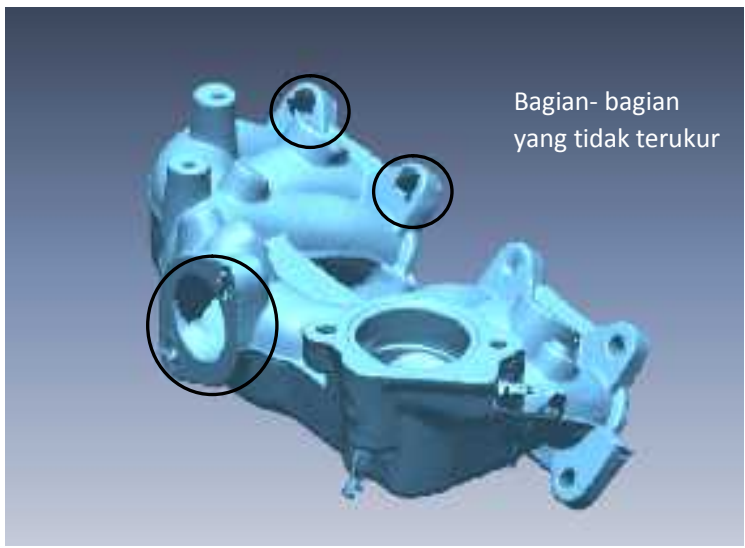

Gambar 6. Bagian yang tidak dapat terukur 3D pemindai

Bagian dalam intake manifold sebagian besar tidak terukur. Solusi yang dilakukan adalah dengan cara membuat geometri dengan analisa fitur primitive dan fitur editing.

d. Pemodelan 3D

Pemodelan 3D dilakukan setelah diperolehnya ukuran dari alat pemindai 3D dan Gauge Califer. Pemodelan 3D ini dilakukan dengan mempertimbangkan:

1. Fungsi dari intake manifold tersebut. Aplikasi yang digunakan untuk keperluan pemodelan adalah Rapidform.

2. Berbasis Fitur, bagian yang tidak terukur namun masih membentuk fitur, dimodelkan berdasarkan fitur

3. Proses manufaktur, fitur yang dibuat harus mudah dimanufaktur, salah satu pertimbangan pada saat pembuatan pola

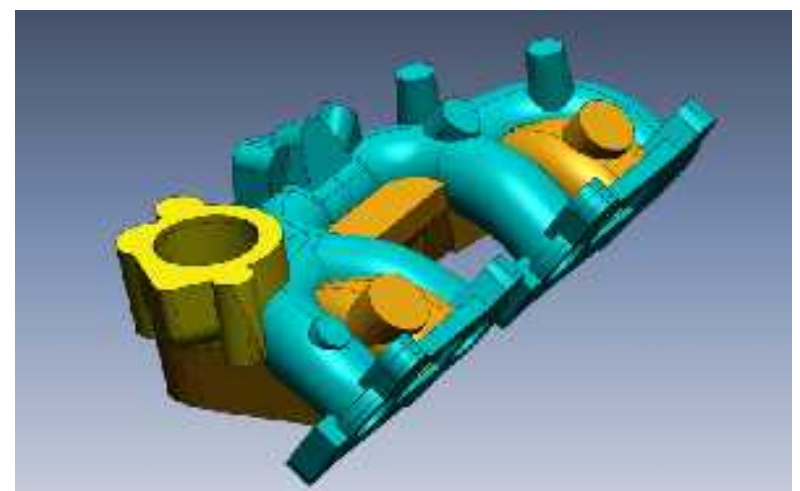

Gambar 7. Hasil pemodelan Intake manifold (digambar dalam aplikasi Rapidform)

Hasil pemodelan geometrik tidak persis sama dengan geometrik dari intake manifold F10 suzuki. Hal ini dikarenakan kami melakukan beberapa modifikasi fitur. Seperti yang telah dijelaskan sebelumnya.

Pemodelan geometrik yang dilakukan dengan pendekatan rakitan, yaitu komponen yang dimodelkan adalah gabungan dari beberapa part, hal ini disebabkan karena:

1. Kompleksitas Intake manifold yang terdiri dari aliran bahan bakar dan aliran air sebagai pemanas. 
2. Pada saat penempatan fitur bagian dalam (yang tidak terlihat) lebih mudah dilakukan dengan sistim multi part.

3. Pertimbangan pada saat proses manufaktur.

e. Pengecekan Incoincident dan interference model 3D

Pengecekan ini adalah pengecekan terhadap kemungkinan terjadi rongga pada model sebagai akibat editing model (Incoincident), atau kemungkinan terjadi irisan atara dua part pada saat assembly (interference). Pengecekan incoincident dengan cara model di-messing, apabila berhasil maka model sudah coincident. Pengecekan interference dapat langsung dilakukan di aplikasi CAD.

\section{KESIMPULAN}

Dari hasil penelitian ini dapat disimpulkan.

1. Intake manifold dapat digambar secara utuh dengan berbasis fitur

2. Pengukuran intake manifold dengan menggunakan 3D pemindai masih belum dapat terukur semua bagian

3. Bagian yang tidak terukur dapat dilakukan dengan pendekatan fitur primitif dan fitur editing

4. Pemilihan semua fitur berdasarkan pertimbangan: fungsi komponen dan proses manufaktur

5. Alat ukur manual dapat digunakan untuk membandingkan dan verikifasi ukuran

6. Tidak terjadi incoincident dan interference.

\section{UCAPAN TERIMA KASIH}

Pada kesempatan ini kami berterima kasih Ir. Eddy Siswanto, MAM. sebagai Kepala BBLM yang telah memberikan kesempatan mendukung kegiatan penelitian ini.

\section{PUSTAKA:}

Campbell John, Castings: The New Metallurgy of Cast metals, Butterworth, 4nd Edition, Burlington, 2006

Dieter Goerge E., Schmidt Linda C., Engineering Design, Mcgraw Hill, 4th Edition, North American, 2009

Hafid et. Al, Membuat Desain Pengecoran dengan Simulasi Adstefan Untuk Menanggulangi Cacat Pada Produk Cor, Jurnal Riset Industri Vol V, No.3, 2011
Jami J. Shah, By (author) Martti Mäntylä, Parametric and Feature-based CAD/CAM

: Concepts, Techniques and Applications, John Wiley and Sons Ltd, 2006

Kelly, David S. Pro/ENGINEER Wildfire Instructor. Mc Graw Hill ISBN 0-07321153-2. 2005

Konica. Konica Minolta Instruction Book Non Contact 3D Digitizer vivid 9i/VI-9i, Konica. 2006

Rapidform. Rapidform Instruction Book, 3D system, USA, 2006 pp. 117-124. ISBN 07695-0984-3.

Rochim, Taufiq. Tujuh Tahapan Rekayasa Peniruan. FTMD-ITB. Makalah Reverse engineering Workshop. PT. PLN (persero), Jakarta 23-24 Mei 2012

Michal Dúbravík, Štefan Kender, Application of reverse engineering techniques in mechanics system services, Elsevier, Procedia Engineering 48 ( 2012 ) 96-104

Lingling Li, Congbo Li, Ying Tang, Yanbin $\mathrm{Du}$, An integrated approach of reverse engineering aided remanufacturing process for worn components, Robotics and Computer-Integrated Manufacturing, Elsivier , Volume 48, December 2017, Pages 39-50

Van Basshuysen Richard., Schafer Fred., Internal Combustion Engine: Basics, Components, System, and Perspectives, SAE International, USA, 2004,

Whitney Daniel E., Mechanical Assemblies: Their Design, Manufacture, and Role in Product Development, Oxford University Press, New York, 2006 